Sharif University of Technology
Scientia Iranica
Transactions E: Industrial Engineering
hCIENTIA

\title{
A game theoretic approach to coordination of pricing, ordering, and co-op advertising in supply chains with stochastic demand
}

\author{
H. Ghashghaei and M. Mozafari* \\ Department of Industrial Engineering, Electronic Branch, Islamic Azad University, Tehran, P.O. Box 14335-499, Iran.
}

Received 10 August 2018; received in revised form 7 March 2019; accepted 4 May 2019

\author{
KEYWORDS \\ Supply chain \\ coordination; \\ Newsboy problem; \\ Pricing; \\ Cooperative \\ advertising; \\ Ordering; \\ Uncertainty; \\ Game theory.
}

\begin{abstract}
The present study aims to investigate the combination of the newsboy problem and the cooperative advertisement problem in the presence of uncertain demand which depends on retail price as well as both local and national advertising expenditures to coordinate pricing, ordering, and advertising decisions in a manufacturer-retailer supply chain. A game theoretic approach was adopted to determine the equilibrium values for decisions. Three different game scenarios based on the newsboy problem model were developed and analyzed: 1) Stackelberg manufacturer game in which the manufacturer as the dominant power plays the role of leader in the market and the follower retailer makes his own best decisions after considering the leader's decisions; 2) Nash equilibrium game in which both manufacturer and retailer are of equal power in the market and make their decisions simultaneously to devise their best strategies; 3) Centralized scenario in which the retailer and manufacturer make the best decisions by means of information sharing and joint cooperation. Equilibrium decisions were made exactly in these scenarios. Some corollaries were also presented and theoretically proved to show the relationships among the variables in both centralized and decentralized supply chains. Finally, some numerical examples were randomly generated and sensitivity analysis was carried out to show the capabilities of the proposed models.
\end{abstract}

(C) 2020 Sharif University of Technology. All rights reserved.

\section{Introduction}

The newsboy problem is a mathematical model used for optimizing the inventory levels. The production and operations management is obligated to estimate the profit of the entire supply chain and make coordinated ordering decisions for all supply chain members for a number of reasons such as supply chain outlook, need for expanding the business to new markets, and decline

*. Corresponding author. Tel.: +982142863000 E-mail address: m_mozafari@iauec.ac.ir (M. Mozafari)

doi: $10.24200 /$ sci. 2019.51588 .2264 in demand. In this regard, pricing and advertising are regarded as effective tools for making coordination among separate property companies as independent members. Decisions in a supply chain can be made in a centralized or decentralized manner. In a centralized structure, a central authority is held responsible for coordinating supply chain activities in order to optimize the entire supply chain performance; however, in a decentralized scheme, the different entities compete with each other to improve their individual performance. In the latter, making coordinated ordering decisions is an imperative issue, which is usually dealt with using a game theoretic approach. In the decentralized structure, different members may be able to simultaneously 
optimize both their individual and whole supply chain performance by coordinating their strategies.

Cooperative advertising is an interactive relationship between manufacturer and retailer in which the manufacturer pays a proportion of advertisement expenditures in order to achieve a higher potential market share, build brand equity, and create motivation at the retail level, while the retailer pays for local advertising costs in order to increase the local demand [1]. In fact, each member undertakes to pay a part of advertising costs for different objectives. Berger [2] carried out the first study on a two-member supply chain in which the manufacturer gives the retailer a discount on the wholesale price as a cooperative advertisement. Therefore, an extensive body of research has been conducted on the cooperative advertising in two-echelon supply chains. Aust and Buscher [3] conducted a comprehensive review of the papers published on cooperative advertising in supply chains over the last 40 years. In addition to the retail advertising expenditures, cooperation rate with the objective of maximizing the total supply chain profit and making coordination among members is also of significance. In this regard, Huang and $\mathrm{Li}$ [4] incorporated an investment of advertising as well as local and national advertising expenditures into their model while taking bargaining and members' risk attitudes into account. They addressed the shift of power from a wholesaler to retailer in new markets such as Walmart and developed three game models including the Stackelberg manufacturer game, Stackelberg retailer game, and cooperative game to examine the cooperative advertising efficiency with respect to transactions between wholesaler and retailer through brand name investments.

Pricing problem that involves determining the price set by retailer and wholesaler is another important decision in the supply chain coordination. In most studies on advertisement decisions, it is assumed that demand is only a function of advertising expenditures which is not influenced by the retail price. However, making pricing decisions is the main task in marketing and distribution channels where pricing and advertising costs are in constant competition with each other to attain supply chain coordination [5]. Given the significant role of game theory in analyzing the supply chain approach, a great body of literature has investigated the role of advertising and pricing in the balance of power among members using game theoretic approaches. Karray and Amin [6] considered cooperative advertising in a network of competing retailers. In their work, the effects of cooperative advertising under two game scenarios (with and without cooperation) were evaluated while both price and advertising costs were considered as decision variables. They showed that when retailers competed for low price levels and high advertising in supply chains, cooperative advertising would not be profitable for either retailer or network. Yan et al. [7] studied the value of the manufacturer's cooperative advertising and its strategic impact on information sharing between the manufacturer and retailer under demand uncertainty. They indicated that information had a remarkable effect on both retailer's and manufacturer's decisions on investing in advertisement. Thus, they concluded that using an advertising agency could contribute to more efficient information sharing and elimination of the distorted information and help both members make the optimal investing decisions. J $\phi$ rgensen and Zaccour [8] studied game theoretic models of cooperative advertising in both static and dynamic environments. Their research comprised two main parts. In the first part, a simple manufacturer-retailer supply chain was studied, and in the second part, more complex supply chains with more than one supplier and one retailer with horizontal interactions were investigated. Alirezaei and Khoshalhan [9] investigated optimal pricing, optimal advertising expenditures, and cooperative advertising decisions in a two-echelon supply chain. They employed Nash game, Stackelberg manufacturer game, Stackelberg retailer game, and cooperative game to analyze the supply chain. Finally, the best settings used for achieving coordination are determined through a bargaining model.

Several researches have been conducted on the joint area of pricing and advertising decisions. He et al. [10] developed a new contract scheme in a twoechelon supply chain when demand was influenced by both retail price and advertising costs. The proposed scheme was a combination of return policy and revenue sharing contract which embodied sales rebate and penalty. They suggested that in the proposed situation, achieving a win-win situation would be probable. Szmerekovsky and Zhang [11] studied pricing decisions in a manufacturer-retailer supply chain when demand was stochastic and influenced by both retail price and advertisement. The model was then analyzed via three games including Stackelberg, Nash, and cooperative games. The obtained results indicated that in a twotier distribution channel, local advertising cost was not appropriate enough for making decisions. Instead, national advertisements run by the manufacturer along with a wholesale price discount to the retailer could yield the desired results. Xie and Wei [5] and Xie and Neyret [12] followed the same approach and analyzed the effects of changing price and advertising functions under Stackelberg, Nash, and cooperative games. Chen [13] examined the effects of advertisement with return policy for a sales problem in a manufacturerretailer supply chain to determine the values of inventory and advertising decision variables in both cooperative and non-cooperative situations. Seyed Esfahani et al. [14] investigated the role of coordination in a 
two-echelon supply chain with advertising and pricedependent demand using four game scenarios including cooperative game, Nash equilibrium, Stackelberg manufacturer game, and Stackelberg retailer game. The authors concluded that in the cooperative condition, advertisements would play a strategic role in making critical decisions. A non-linear demand function was applied to the model. Dridi and Ben Youssef [1] considered a supply chain with competing retailers and a demand depending on both price and national advertising expenditures. Three games including full cooperative, parallel cooperative, and non-cooperative games were developed to assess the surplus of customer demands. Moreover, they considered a new linear additive form of demand function in a cooperative advertising supply that comprised a monopolistic manufacturer and two competing retailers. In order to maximize the total profit, three game scenarios were presented and the profits were compared. Naimi Sadigh et al. [15] took into account a multi-echelon distribution channel consisting of multiple suppliers, one manufacturer, and several retailers while the demand was affected by both price and advertisement. They used a noncooperative Nash game to obtain the optimal values of decision variables including economic order quantity, price, inventory level, and advertising expenditures.

Numerous studies have been conducted on the coordination of pricing and advertising decisions; however, few of them have explored the uncertainty factor. Choi [16] suggested that changing the demand function could yield different outcomes. Aust [17] analyzed cooperative advertising model and pricing decisions using four game theoretic scenarios including Nash game, Stackelberg manufacturer game, Stackelberg retailer game, and cooperative game. The authors extended the existing models and took the roles of bargaining and risk into account. It was shown that under a cooperative condition, the total profit would be maximized. Moreover, they suggested that customer satisfaction could be improved by decreasing price and increasing advertising expenditures provided that a coordinated structure between the manufacturer and retailer be present. Ke et al. [18] studied pricing competition in a two-echelon supply chain consisting of one manufacturer and two competing retailers while the manufacturing costs, sales costs, and market bases were all regarded as uncertain fuzzy variables. They investigated the equilibrium behaviors of the supply chain members in three decentralized game models.

Table 1 compares the general settings of this paper with those of the related literature. As observed in Table 1, the combination of newsboy problem and cooperative advertisement used for determining the joint ordering and advertising decisions has been rarely studied in the related literature (e.g., [20,21]). Amirtaheri et al. [20] studied a joint pricing, ordering, and cooperative advertising problem in a bi-level decentralized supply chain, comprising one manufacturer and one distributer, and considered a deterministic demand function. Zhou et al. [21] addressed a joint cooperative advertising and ordering problem in a two-echelon supply chain consisting of a riskaverse leader manufacturer and a risk-averse follower retailer. They assumed a random demand depending on the manufacturer's global advertising as well as the retailer's local advertising. However, their proposed demand function did not include pricing impacts. A simultaneous relationship between the manufacturer and retailer was also neglected. The main contribution of this paper is to present a combination of the newsboy problem and cooperative advertisement problem considering stochastic demand to coordinate ordering, pricing, and advertising decisions in a two-echelon supply chain. To this end, a new additive demand function is presented in this study which depends on retail price as well as both local and national advertising expenditures and affected by a random factor with a uniform distribution. Three different scenarios are also analyzed: 1) the centralized scenario in which the retailer and manufacturer cooperate and make the global best decisions; 2) the manufacturer-leader Stackelberg scenario in which the manufacturer as the dominant power plays the role of the leader and makes his decisions independently; then, the retailer as the follower chooses his own best strategies after examining the leader's decisions; and 3) the Nash game scenario in which both manufacturer and retailer have the same power and make their decisions simultaneously. The rest of the paper is structured as follows. Section 2 introduces the main assumptions of the problem under study and the relevant notations. Section 3 proposes a model of the problem under a centralized channel scenario and evaluates the optimal decisions. Section 4 presents the mathematical models of the problem under two decentralized channel scenarios to obtain the equilibrium decisions. In Section 5, some numerical examples are randomly generated and the results are discussed. Sensitivity analysis is also carried out on the main parameters of the proposed demand function. Finally, Section 6 concludes the study.

\section{Problem definition}

Consider a single-product two-echelon supply chain including one manufacturer and one retailer. Demand is subject to both price and advertising expenditures and the retailer is able to boost product demand by price discount offers and/or advertisement. On the contrary, advertisement expenditures reduce the retailer profit which is a demotivating factor from the retailer's viewpoint. As a result, the manufacturer undertakes to pay for a proportion of advertising costs 
Table 1. Comparison of the general settings of the current paper and related literature.

\begin{tabular}{|c|c|c|c|c|c|c|c|}
\hline Ref. & $\begin{array}{l}\text { Channel } \\
\text { structure }\end{array}$ & Decisions & $\begin{array}{c}\text { Demand } \\
\text { type }\end{array}$ & Uncertainty & $\begin{array}{c}\text { Advertising } \\
\text { type }\end{array}$ & $\begin{array}{c}\text { Centralized } \\
\text { structure }\end{array}$ & $\begin{array}{c}\text { Decentralized } \\
\text { structure }\end{array}$ \\
\hline$[10]$ & Two-echelon & $\begin{array}{l}\text { - Pricing } \\
\text { - Ordering } \\
\text { - Advertising }\end{array}$ & $\begin{array}{l}\text { Price and } \\
\text { advertising } \\
\text { dependent }\end{array}$ & $\begin{array}{c}\text { Uniform } \\
\text { distribution }\end{array}$ & Local advertising & No & - Stackelberg equilibrium \\
\hline$[12]$ & Two-echelon & $\begin{array}{l}\text { - Pricing } \\
\text { - Advertising }\end{array}$ & $\begin{array}{l}\text { Price and } \\
\text { advertising } \\
\text { dependent }\end{array}$ & No & $\begin{array}{l}\text { Cooperative } \\
\text { advertising }\end{array}$ & Yes & $\begin{array}{l}\text { - Nash equilibrium } \\
\text { - Stackelberg equilibrium }\end{array}$ \\
\hline$[5]$ & Two-echelon & $\begin{array}{l}\text { - Pricing } \\
\text { - Advertising }\end{array}$ & $\begin{array}{l}\text { Price and } \\
\text { advertising } \\
\text { dependent }\end{array}$ & No & $\begin{array}{l}\text { Cooperative } \\
\text { advertising }\end{array}$ & Yes & - Stackelberg equilibrium \\
\hline$[14]$ & Two-echelon & $\begin{array}{l}\text { - Pricing } \\
\text { - Advertising }\end{array}$ & $\begin{array}{l}\text { Price and } \\
\text { advertising } \\
\text { dependent }\end{array}$ & No & $\begin{array}{l}\text { Cooperative } \\
\text { advertising }\end{array}$ & Yes & $\begin{array}{l}\text { - Nash equilibrium } \\
\text { - Stackelberg equilibrium }\end{array}$ \\
\hline$[19]$ & Two-echelon & $\begin{array}{l}\text { - Pricing } \\
\text { - Advertising } \\
\text { - Ordering }\end{array}$ & $\begin{array}{l}\text { Price and } \\
\text { advertising } \\
\text { dependent }\end{array}$ & No & $\begin{array}{c}\text { Local } \\
\text { advertising }\end{array}$ & Yes & - Stackelberg equilibrium \\
\hline$[9]$ & Two-echelon & $\begin{array}{l}\text { - Pricing } \\
\text { - Advertising }\end{array}$ & $\begin{array}{l}\text { Price and } \\
\text { advertising } \\
\text { dependent }\end{array}$ & No & $\begin{array}{l}\text { Cooperative } \\
\text { advertising }\end{array}$ & Yes & $\begin{array}{l}\text { - Nash equilibrium } \\
\text { - Stackelberg equilibrium }\end{array}$ \\
\hline$[13]$ & Two-echelon & $\begin{array}{l}\text { - Pricing } \\
\text { - Advertising }\end{array}$ & $\begin{array}{l}\text { Price and } \\
\text { advertising } \\
\text { dependent }\end{array}$ & No & $\begin{array}{l}\text { Cooperative } \\
\text { advertising }\end{array}$ & No & - Stackelberg equilibrium \\
\hline$[1]$ & Two-echelon & $\begin{array}{l}\text { - Pricing } \\
\text { - Advertising }\end{array}$ & $\begin{array}{l}\text { Price and } \\
\text { advertising } \\
\text { dependent }\end{array}$ & No & $\begin{array}{c}\text { Local } \\
\text { advertising }\end{array}$ & Yes & - Stackelberg equilibrium \\
\hline$[6]$ & Two-echelon & $\begin{array}{l}\text { - Pricing } \\
\text { - Advertising }\end{array}$ & $\begin{array}{l}\text { Advertising } \\
\text { dependent }\end{array}$ & No & $\begin{array}{c}\text { Local } \\
\text { advertising }\end{array}$ & Yes & - Stackelberg equilibrium \\
\hline$[17]$ & Two-echelon & $\begin{array}{l}\text { - Pricing } \\
\text { - Advertising }\end{array}$ & $\begin{array}{l}\text { Price and } \\
\text { advertising } \\
\text { dependent }\end{array}$ & No & Co-op & Yes & $\begin{array}{l}\text { - Nash equilibrium } \\
\text { - Stackelberg equilibrium }\end{array}$ \\
\hline$[7]$ & Two-echelon & $\begin{array}{l}\text { - Pricing } \\
\text { - Advertising }\end{array}$ & $\begin{array}{l}\text { Price and } \\
\text { advertising } \\
\text { dependent }\end{array}$ & $\begin{array}{c}\text { Normal } \\
\text { distribution }\end{array}$ & $\begin{array}{c}\text { Local } \\
\text { advertising }\end{array}$ & No & - Stackelberg equilibrium \\
\hline$[15]$ & Three-echelon & $\begin{array}{l}\text { - Pricing } \\
\text { - Advertising }\end{array}$ & $\begin{array}{l}\text { Price and } \\
\text { advertising } \\
\text { dependent }\end{array}$ & No & $\begin{array}{c}\text { Local } \\
\text { advertising }\end{array}$ & No & - Nash equilibrium \\
\hline$[18]$ & Two-echelon & - Pricing & $\begin{array}{c}\text { Price } \\
\text { dependent }\end{array}$ & Fuzzy & No & No & - Stackel berg equilibrium \\
\hline$[20]$ & Two-echelon & $\begin{array}{l}\text { - Pricing } \\
\text { - Ordering } \\
\text { - Advertising }\end{array}$ & $\begin{array}{l}\text { Price and } \\
\text { advertising } \\
\text { dependent }\end{array}$ & No & $\begin{array}{l}\text { Cooperative } \\
\text { advertising }\end{array}$ & No & - Stackelberg equilibrium \\
\hline$[21]$ & Two-echelon & $\begin{array}{l}\text { - Ordering } \\
\text { - Advertising }\end{array}$ & $\begin{array}{l}\text { Advertising } \\
\text { dependent }\end{array}$ & $\begin{array}{l}\text { Uniform and } \\
\text { normal } \\
\text { distribution }\end{array}$ & $\begin{array}{l}\text { Cooperative } \\
\text { advertising }\end{array}$ & Yes & - Stackelberg equilibrium \\
\hline $\begin{array}{l}\text { Current } \\
\text { paper }\end{array}$ & Two-echelon & $\begin{array}{l}\text { - Pricing } \\
\text { - Ordering } \\
\text { - Advertising }\end{array}$ & $\begin{array}{l}\text { Price and } \\
\text { advertising } \\
\text { dependent }\end{array}$ & $\begin{array}{c}\text { Uniform } \\
\text { distribution }\end{array}$ & $\begin{array}{l}\text { Cooperative } \\
\text { advertising }\end{array}$ & Yes & $\begin{array}{l}\text { - Nash equilibrium } \\
\text { - Stackelberg equilibrium }\end{array}$ \\
\hline
\end{tabular}


in order to encourage the retailer to advertise its products and stimulate product demand throughout the chain that can improve the retailer's profit margin as well. Moreover, demand is presumably stochastic; in other words, demand is influenced by not only both pricing and advertising decisions but also a stochastic factor.

The problem mentioned in this study takes into account the assumptions of newsboy model. The objective is to determine the optimal values of key decision variables in a two-echelon supply chain for which a coordination among members is established. The key variables are economic order quantity, manufacturer's and retailer's participation rates in advertising expenditures, and retail price and wholesale price. In the newsboy problem, before the sales period, the retailer decides on retail price, local advertising costs, and its economic lot size, while the manufacturer determines the national advertising expenditures and wholesale price.

\subsection{Assumptions}

The following assumptions are considered in the manufacturer's and retailer's models:

1. The channel produces a single commodity;

2. The demand for the commodity is considered as a function which depends linearly on retail price and nonlinearly on the local and national advertising expenditures;

3. The demand is stochastic;

4. Ordering decisions follow the assumptions of newsboy problem;

5. The planning horizon is of single-period type and the surplus inventory at the end of this period has no salvage value;

6. No shortage is allowed.

\subsection{Notations}

The following notations are used to formulate the problem:

$\begin{array}{ll}F(x) & \begin{array}{l}\text { Cumulative distribution function of } \\ \text { demand }\end{array} \\ f(x) & \text { Probability density function of demand } \\ \mu & \text { Expected value of demand } \\ C & \text { Unit production cost } \\ q & \text { Ordering quantity } \\ p & \text { Retail price } \\ n & \text { Manufacturer's advertising expenditure } \\ e & \text { Retailer's advertising expenditure } \\ D(p, n, e, \varepsilon) & \text { Stochastic demand function } \\ h(n, e) & \text { Advertising-dependent definite } \\ & \text { function }\end{array}$

$\begin{array}{ll}d(p) & \text { Price-dependent definite function } \\ \varepsilon & \text { Stochastic variable } \\ z & \text { Stocking factor } \\ \Theta(z) & \text { Expected value of shortage } \\ \pi_{s} & \text { Manufacturer's benefit } \\ \pi_{r} & \text { Retailer's benefit } \\ \pi_{c} & \text { Supply chain benefit }\end{array}$

It is assumed that demand function is an additive stochastic function that depends on price and both local and national advertising expenditures, as defined in the following:

$$
D(p, n, e, \varepsilon)=d(p)+h(n, e)+\varepsilon,
$$

where $d(p)$ shows the demand dependency on retail price and is defined as a linear function $d(p)=a-b p$ in which $a$ is the market scaling factor, $b$ is the price elasticity of demand coefficient, and $h(n, e)$ represents the relation between advertising expenditures and demand and is given by $h(n, e)=k_{1} \sqrt{n}+k_{2} \sqrt{e}$ as a nonlinear function, where $k_{1}$ is the demand for the manufacturer's advertising costs elasticity coefficient and $k_{2}$ is the demand for the retailer's advertising costs elasticity coefficient. $\varepsilon$ is a random variable with uniform distribution function at $[\mathrm{a}, \mathrm{b}]$ interval.

According to the notations and the problem assumptions mentioned above, in the following sections, the problem is modeled and the optimal values of decision variables are explored in three different power scenarios.

\section{Centralized channel}

In this scenario, the manufacturer and retailer completely cooperate and form an integrated centralized supply chain. In this situation, the global optimum solution of the system is obtained by maximizing the total profit of the entire supply chain while no obstacle is in the way of obtaining the solution. The profit function of the entire supply chain is formulated as follows:

$$
\begin{aligned}
& \pi_{c}(q, p, n, e)=p E[\min (D, q)]-c q-n-e, \\
& (q, p, n, e) \in \arg \max \pi_{c}
\end{aligned}
$$

where $E[\min (D, q)]$ indicates the expected retail sales. In order to calculate the expected sales value through an approach similar to the work of [22], the following stocking factor $z$ is initially defined by variable change:

$$
z=q-d(p)-h(n, e)
$$

Now, using the variable change, the set of decision variables $(q, p, n, e)$ is converted to the set of variables 
$(z, p, n, e)$, and the expected sales value is obtained as a function of the stochastic demand:

$$
\begin{aligned}
& E[\min (D, q)]=E[\min (d(p)+h(n, e)+\varepsilon, z \\
& \quad+d(p)+h(n, e))] \\
& =E[\min (z, \varepsilon)]+d(p)+h(n, e) .
\end{aligned}
$$

Then, $E[\min (z, \varepsilon)]$ is computed as follows:

$$
\begin{aligned}
E[\min (z, \varepsilon)]= & \int_{A}^{Z} x f(x)+\int_{z}^{B} z f(x) d x=\int_{A}^{B} x f(x) d x \\
& -\int_{Z}^{B}(x-z) f(x) d x, \\
E[\min (z, \varepsilon)]= & \int_{A}^{Z} x f(x)+\int_{z}^{B} z f(x) d x=\int_{A}^{B} x f(x) d x \\
& -\int_{z}^{B}(x-z) f(x) d x=\mu-\Theta(z),
\end{aligned}
$$

where $\Theta(z)$ is given by:

$$
\Theta(z)=\int_{z}^{B}(x-z) f(x) d x .
$$

As a result, the profit function of the entire supply chain in the centralized scenario is rewritten as follows:

$$
\begin{gathered}
\pi_{c}(p, z, n, e)=p(E[\min (z, \varepsilon)]+d(p)+h(n, e)) \\
-c q-n-e=p(E[\min (z, \varepsilon)]+d(p)+h(n, e)) \\
-c(z+d(p)+h(n, e))-n-e
\end{gathered}
$$

Lemma 1: In the centralized situation, the supply chain's total profit function is pseudo-concave.

\section{Proof: See Appendix A.}

The optimal values of the manufacturer's and retailer's decision variables are calculated using the derivatives of the profit function.

$$
\begin{aligned}
& \frac{\partial \pi_{c}}{\partial z}=0 \Rightarrow F(z)=1-\frac{c}{p}, \\
& \frac{\partial \pi_{c}}{\partial p}=0 \Rightarrow p=\frac{\mu-\Theta(z)+a+h(n, e)+c b}{2 b} .
\end{aligned}
$$

Then, by solving a two-equation system with two variables in Eqs. (9) and (10) for the given $z$ and $p$, the optimal value of $z^{*}$ is obtained as follows:

$$
\begin{aligned}
& \left(\mu-\Theta\left(z^{*}\right)+a\right)\left(1-F\left(z^{*}\right)\right)+\frac{k_{1}^{2}+k_{2}^{2}}{2} \times c F\left(z^{*}\right) \\
& +c b\left(1-F\left(z^{*}\right)\right)-2 c b=0 .
\end{aligned}
$$

Since Eq. (11) shows the optimal value of $z^{*}$, the optimal values of the other decision variables including retail price, lot size, retailer's local advertising expenditures, and manufacturer's national advertising costs can be obtained. The optimal retail price is given in Eq. (12):

$$
p_{c}^{*}=\frac{c}{1-F\left(z^{*}\right)} .
$$

When partial derivative of the total profit function with respect to local advertising variable is equal to zero, the retailer's local advertising expenditures are calculated as follows:

$$
\frac{\partial \pi_{c}}{\partial e}=0 \Rightarrow \quad e_{c}^{*}=\left(\frac{k_{2}\left(p^{*}-c\right)}{2}\right)^{2} .
$$

The optimal value of the manufacturer's national advertising expenditures can be calculated through the same approach:

$$
\frac{\partial \pi_{c}}{\partial n}=0 \Rightarrow \quad n_{c}^{*}=\left(\frac{k_{1}\left(p^{*}-c\right)}{2}\right)^{2} .
$$

Finally, the optimal value of the ordering lot size is:

$$
\begin{aligned}
q_{c}^{*}= & z^{*}+d(p)+h(n, e)=z^{*} \\
& +\left(a-b p^{*}+k_{1} \sqrt{n^{*}}+k_{2} \sqrt{e^{*}}\right) .
\end{aligned}
$$

\section{Decentralized channel}

In this section, the problem in a decentralized channel is studied where the manufacturer and retailer decide on their strategies and individual profits. Two different scenarios are considered: the Stackelberg manufacturer-leader game and Nash equilibrium game.

\subsection{Stackelberg manufacturer-leader equilibrium}

In this scenario, the manufacturer as the leader makes his own decisions from the very beginning. Subsequently, the retailer as the follower chooses the best reaction to the manufacturer's strategy and decides on the variables under his control. Hence, the problem model in the Stackelberg game scenario is a bi-level programming model, while the manufacturer sub-model and the retailer sub-model are at the higher and lower levels, respectively.

$$
\begin{array}{ll}
\operatorname{Max} & \pi_{s}(w, n)=(w-c) q-n \\
\text { s.t. } & (p, q, e) \in \arg \max \pi_{r}=p(E[\min (D(p, n, e), q]) \\
& -w q-e .
\end{array}
$$


In order to solve the obtained bi-level programming model in the Stackelberg manufacturer game scenario, the optimality conditions of the lower-level model are primarily added to the space constraints of the upper-level model and then, the profit function of the leader player is maximized considering the best reaction of the follower player. Consequently, the bilevel programming model is converted to its equivalent single-level programming model.

The retailer profit function is rewritten by changing the variable of Eq. (3):

$$
\begin{aligned}
\pi_{r}(p, q, e) & =p(E[\min (D(p, n, e), q])-w q-e \\
& =p(E[\min (z, \varepsilon)]+d(p)+h(n, e)) \\
& -w(z+d(p)+h(n, e))-e .
\end{aligned}
$$

Lemma 2: The retailer's profit function is pseudoconcave according to the retailer's decision variables.

Proof: See Appendix B.

By taking Lemma 2 into account, it can be concluded that the optimal values of the retailer's decision variables including retail price, local and national advertising costs, and economic order quantity uniquely are available and calculated in the following manner:

$$
\begin{aligned}
\frac{\partial \pi_{r}}{\partial p} & =0 \Rightarrow p(w)=\frac{w}{1-F(z)} \\
\frac{\partial \pi_{r}}{\partial e} & =0 \Rightarrow e(w)=\left(\frac{k_{2}^{2} w F(z)}{2(1-F(z))}\right)^{2} \\
z= & q-(d(p)+h(n, e))=q \\
& -\left(a-b p+k_{1} \sqrt{n}+k_{2} \sqrt{e(w)}\right)=q(w)=z \\
& +a-b\left(\frac{w}{1-F(z)}\right)+k_{1} \sqrt{n}+k_{2} \sqrt{e(w)} \\
& =q(w)=z+a-b\left(\frac{w}{1-F(z)}\right)+k_{1} \sqrt{n} \\
& +\left(\frac{k_{2}^{2} w F(z)}{2(1-F(z))}\right) ;
\end{aligned}
$$

Thus, we can obtain the followings:

$$
\begin{aligned}
& p(w)=\frac{w}{1-F(z)} \\
& e(w)=\left(\frac{k_{2}^{2} w F(z)}{2(1-F(z))}\right)^{2},
\end{aligned}
$$

$$
\begin{aligned}
q(w) & =z+a-b\left(\frac{w}{1-F(z)}\right)+k_{1} \sqrt{n} \\
& +\left(\frac{k_{2}^{2} w F(z)}{2(1-F(z))}\right) .
\end{aligned}
$$

By incorporating the optimal values of the retailer's decision variables into the manufacturer's model, the manufacturer's profit function can be rewritten as follows:

$$
\begin{aligned}
& \pi_{s}(w, n)=(w-c) q-n \\
& \pi_{s}(w, n)=(w-c) q-n \Rightarrow \\
& (w-c)\left(z+a-b\left(\frac{w}{1-F(z)}\right)+k_{1} \sqrt{n}\right. \\
& \left.\quad+\left(\frac{k_{2}^{2} w F(z)}{2(1-F(z))}\right)\right)
\end{aligned}
$$

Lemma 3: In Stackelberg game, the manufacturer's profit function is pseudo-concave regarding the manufacturer's decision variables.

\section{Proof: See Appendix C.}

Considering the concavity property of the manufacturer's profit function, one can obtain the manufacturer's optimal decisions by taking the derivatives of the manufacturer's profit function with respect to its decision variables.

$$
\begin{aligned}
& \frac{\partial \pi_{s}}{\partial n}=0 \Rightarrow n=\left(\frac{(w-c) k_{1}}{2}\right)^{2} \\
& \frac{\partial \pi_{s}}{\partial w}=0 \Rightarrow(w-c) q-n \\
& =(w-c)\left(z+a-b\left(\frac{w}{1-F(z)}\right)+k_{1} \sqrt{n}\right. \\
& \left.+\left(\frac{k_{2}^{2} w F(z)}{2(1-F(z))}\right)\right)=(w-c) \\
& \left(z+a-b\left(\frac{w}{1-F(z)}\right)+\frac{(w-c) k_{1}^{2}}{2}\right. \\
& \left.+\left(\frac{k_{2}^{2} w F(z)}{2(1-F(z)}\right)\right) \Rightarrow w^{*} \\
& =\frac{2(1-F(z))(z+a)+2 b c-2 c k_{1}^{2}(1-F(z))-c k_{2}^{2} F(z)}{4 b-2 k_{1}^{2}(1-F(z))-2 k_{2}^{2} F(z)}
\end{aligned}
$$

The optimal values of retail price, local and national advertising expenditures, and economic order quantity 
can be calculated by solving the Stackelberg model, as shown in the following:

$$
\begin{aligned}
& w^{*}= \\
& \frac{2(1-F(z))(z+a)+2 b c-c k_{1}^{2}(1-F(z))-c k_{2}^{2} F(z)}{4 b-2 k_{1}^{2}(1-F(z))-2 k_{2}^{2} F(z)} \\
& n^{*}=\left(\frac{\left(w^{*}-c\right) k_{1}}{2}\right)^{2} \\
& q^{*}=z+a-b\left(\frac{w^{*}}{1-F(z)}\right)+\frac{\left(w^{*}-c\right) k_{1}^{2}}{2} \\
& \quad+\left(\frac{k_{2}^{2} w^{*} F(z)}{2(1-F(z))}\right) \\
& p^{*}=\frac{w^{*}}{1-F(z)}, \\
& e^{*}=\left(\frac{k_{2} w^{*} F(z)}{2(1-F(z))}\right)^{2} .
\end{aligned}
$$

\subsection{Nash equilibrium}

In this scenario, it is assumed that both manufacturer and retailer are separate property companies that independently take their strategies without cooperation. Moreover, both manufacturer and retailer have equal power in the market and apply their decisions to the market at the same time. In this situation, both players concurrently pursue the maximization of their individual profits, while the total profit of the supply chain is ignored. Thus, the Nash equilibrium solution is obtained when the profit functions of both players are simultaneously maximized.

The optimality conditions of the manufacturer's sub-model are as follows. Using the variable change in Eq. (3), the manufacturer's profit function can be formulated as follows:

$$
\pi_{s}(w, n)=(w-c)(z+d(p)+h(n, e))-n .
$$

By considering Lemma 3 and due to the concavity property of the manufacturer's profit function, the optimal values of the manufacturer's decision variables can be obtained by setting partial derivatives of the profit function with regard to decision variables equal to zero.

$$
\frac{\partial \pi_{s}}{\partial n}=0 \Rightarrow n=\left(\frac{(w-c) k_{1}}{2}\right)^{2}
$$

The derivative relation cannot be used for computing the optimum wholesale price. Therefore, it is assumed that the wholesale price $w$ is equal to the production cost $C$ multiplied by a constant factor $\beta$. In other words, $w=\beta c$, thus $\beta>1$. By replacing $w$, the optimal advertising expenditures are calculated as shown in the following:

$$
n=\left(\frac{(w-c) k_{1}}{2}\right)^{2}=\left(\frac{c(\beta-1) k_{1}}{2}\right)^{2}
$$

The retailer's profit function is formulated as follows:

$$
\begin{aligned}
\pi_{r}(p, q, e) & =p[E(\min (D(p, n, e), q)]-w q-e \\
& =p(E[\min (z, \varepsilon)]+d(p)+h(n, e)) \\
& -w[z+d(p)+h(n, e)]-e, \\
\pi_{r}(p, q, e) & =p(E[\min (z, \varepsilon)]+d(p)+h(n, e)) \\
& -w[z+d(p)+h(n, e)]-e .
\end{aligned}
$$

According to Lemma 2, since the retailer's profit function is concave, the optimal values of the retailer's decision variables are accessible by setting partial derivatives of the profit function with regard to decision variables equal to zero:

$$
\begin{aligned}
& \frac{\partial \pi_{r}}{\partial p}=0 \Rightarrow p(w)=\frac{w}{1-F(z)} \Rightarrow p=\frac{\beta c}{1-F(z)}, \\
& \frac{\partial \pi_{r}}{\partial e}=0 \Rightarrow e=\left(\frac{\beta k_{2} F(z)}{2(1-F(z)}\right)^{2}, \\
& q=z+a-b\left(\frac{\beta c}{1-F(z)}\right)+c k_{1}^{2}+\left(\frac{\beta k_{2}^{2} F(z)}{2(1-F(z))}\right) .
\end{aligned}
$$

As a result, the Nash equilibrium point of the problem is obtained by solving both manufacturer's and retailer's sub-models simultaneously in the following:

$$
\begin{aligned}
w^{*} & =\beta c, \\
n^{*} & =\left(\frac{c(\beta-1) k_{1}}{2}\right)^{2}, \\
p^{*} & =\frac{\beta c}{1-F(z)}, \\
e^{*} & =\left(\frac{\beta k_{2} F(z)}{2(1-F(z))}\right)^{2}, \\
q^{*} & =z+a-b\left(\frac{\beta c}{1-F(z)}\right)+c k_{1}^{2}+\left(\frac{\beta k_{2}^{2} F(z)}{2(1-F(z))}\right) .
\end{aligned}
$$

By comparing the obtained solutions of the decentralized channels with those of the centralized channel, the following outcomes are obtained:

\section{Corollary 1:}

$$
e_{d}^{*}<e_{c}^{*}, n_{d}^{*}<n_{c}^{*}, p_{d}^{*}>p_{c}^{*} \quad \text { and } q_{d}^{*}<q_{c}^{*} .
$$

Proof: See Appendix D.

Corollary 1 indicates that in the decentralized channels (Stackelberg, manufacturer-leader, and Nash scenarios), the value of retail price is always greater than 
that in the centralized channel scenario. In fact, the retailer is able to decrease retail price because he does not have to pay the wholesale price to the manufacturer under the centralized scenario. Besides, both local and national advertising expenditures of the decentralized channels are lower than those of the centralized channel which is mainly due to the competition between manufacturer and retailer in the decentralized scenarios, making the two parties unwilling to raise their own share of advertising. As a result, the whole supply chain earns more demand and consequently, more profit in the centralized channel which leads to an increase in the economic order size.

Corollary 2: $n_{d}^{*} / e_{d}^{*}<n_{c}^{*} / e_{c}^{*}$.

Proof: See Appendix E.

Corollary 2 implies that the retailer should always spend a greater share of advertising expenditure to increase the demand and his individual profit under the decentralized channel scenarios, while the manufacturer is motivated to spend more time on advertising in the centralized channel, thus increasing the profit of the whole supply chain. Therefore, the ratio of local advertising expenditure to national advertising expenditure in the decentralized channel scenarios is always lower than that in the centralized scenario.

Corollary 3: $d n_{d}^{*} / d k_{1}>0, d e_{d}^{*} / d k_{2}>0, \partial q_{d}^{*} / d k_{2}>$ 0 and $\partial q_{d}^{*} / d k_{1}>0$

Proof: See Appendix F.

According to Corollary 3, the greater the national/ local advertising elasticity of demand, the more national/local advertising expenditures by the manufacturer/retailer in the decentralized channel. Moreover, when demand is elastic, an increase in the advertising expenditures of the two parties leads to an increase in the total demand. Consequently, the retailer's orders will be more due to the greater volume of selling. In other words, a uniform increment in $k_{1}$ and $k_{2}$ results in an increment in national and local advertising expenditures, respectively. This outcome can be extended to the centralized channel.

Corollary 4: $d w / d \beta>0$ and $d p^{*} / d \beta>0$

Proof: See Appendix G.

Since the factor $\beta$ determines the profit margin of the manufacturer, Corollary 4 indicates that the more margin the manufacturer chooses, the higher the wholesale price is and therefore, the higher the price offered by the retailer. It means an increment in $\beta$ which leads to an increment in the wholesale and retail prices.

Based on the aforementioned statements, Table 2 shows the optimal values of decision variables including retail price, wholesale price, local and national advertising expenditures, and economic order quantity for the optimum solutions of the three considered games, i.e., the Stackelberg game, Nash equilibrium, and centralized channel scenario.

\section{Numerical results}

In order to evaluate the performance of the proposed models and the obtained results, several problem instances are investigated in this section. It is assumed that random variable $\varepsilon$ has a uniform distribution function at $[-1000,1000]$ interval and $\beta=1.1$. The other parameters are randomly selected from the defined ranges provided in Table 3 . The optimum solutions to all five problem instances presented in Table 4 are

Table 2. The equilibrium solution in the three game settings.

\begin{tabular}{|c|c|c|c|}
\hline & Centralized & Stackelberg manufacturer-leader game & Nash game \\
\hline$p$ & $p_{c}^{*}=\frac{c}{1-F\left(z^{*}\right)}$ & $p^{*}=\frac{w^{*}}{1-F(z)}$ & $p^{*}=\frac{\beta c}{1-F(z)}$ \\
\hline$n$ & $n_{c}^{*}=\left(\frac{k_{1}\left(p^{*}-c\right)}{2}\right)^{2}$ & $n^{*}=\left(\frac{\left(w^{*}-c\right) k_{1}}{2}\right)^{2}$ & $n^{*}=\left(\frac{c(\beta-1) k_{1}}{2}\right)^{2}$ \\
\hline e & $e_{c}^{*}=\left(\frac{k_{2}\left(p^{*}-c\right)}{2}\right)^{2}$ & $e^{*}=\left(\frac{k_{2} w^{*} F(z)}{2(1-F(z))}\right)^{2}$ & $e^{*}=\left(\frac{\beta k_{2} F(z)}{2(1-F(z))}\right)^{2}$ \\
\hline$q$ & $\begin{aligned} q^{*}= & z^{*}+\left(a-b p^{*}+k_{1} \sqrt{n^{*}}\right. \\
& \left.+k_{2} \sqrt{e^{*}}\right)\end{aligned}$ & $\begin{aligned} q^{*}= & z+a-b\left(\frac{w^{*}}{1-F(z)}\right) \\
& +\frac{\left(w^{*}-c\right) k_{1}^{2}}{2}+\left(\frac{k_{2}^{2} w^{*} F(z)}{2(1-F(z))}\right)\end{aligned}$ & $\begin{aligned} q^{*}= & z+a-b\left(\frac{\beta c}{1-F(z)}\right) \\
& +c k_{1}^{2}+\left(\frac{\beta k_{2}^{2} F(z)}{2(1-F(z))}\right)\end{aligned}$ \\
\hline$w$ & - & $w^{*}=\frac{2(1-F(z))(z+a)+2 b c-c k_{1}^{2}(1-F(z))-c k_{2}^{2} F(z)}{4 b-2 k_{1}^{2}(1-F(z))-2 k_{2}^{2} F(z)}$ & $w^{*}=\beta c$ \\
\hline
\end{tabular}


Table 3. Range of parameters.

\begin{tabular}{ccccc}
\hline Parameters & $\boldsymbol{a}$ & $\boldsymbol{b}$ & $\boldsymbol{k}_{\mathbf{1}}$ & $\boldsymbol{k}_{\mathbf{2}}$ \\
\hline Ranges & {$[2000-3500]$} & {$[0.010-0.015]$} & {$[0.01-0.05]$} & {$[0.01-0.05]$} \\
\hline
\end{tabular}

Table 4. The problem instances.

\begin{tabular}{ccccc}
\hline Problems & $\boldsymbol{a}$ & $\boldsymbol{b}$ & $\boldsymbol{k}_{\mathbf{1}}$ & $\boldsymbol{k}_{\mathbf{2}}$ \\
\hline Instance 1 & 2,000 & 0.010 & 0.01 & 0.01 \\
Instance 2 & 3,000 & 0.015 & 0.02 & 0.05 \\
Instance 3 & 3,000 & 0.012 & 0.04 & 0.02 \\
Instance 4 & 3,000 & 0.010 & 0.02 & 0.04 \\
Instance 5 & 3,500 & 0.010 & 0.05 & 0.05 \\
\hline
\end{tabular}

calculated in the three scenarios (manufacturer-leader, Nash, and centralized channel), the results of which are shown in Table 5 .

Considering the results summarized in Table 5, the author can examine the influence of scenarios on the prices, local and national advertising expenditures, and profits. The maximum retail prices are observed both in manufacturer-leader and Nash equilibria scenarios, whereas the minimum retail prices are observed in the centralized channel. The comparison of the two decentralized scenario reveals that higher retail prices are often observed in the manufacturer-leader equilibria scenario since the manufacturer as the leader imposes higher wholesale prices on the retailer who consequently has to set higher retail prices.

The local and national advertising expenditures are considered as the highest prices in the centralized scenario. Given the two decentralized scenarios, the retailer's local advertising expenditure is higher in the manufacturer-leader equilibria than that in the Nash equilibria because the retailer has a lower position in the channel. Of note, when the advertising elasticity coefficient is equal for both manufacturer and retailer (Instance 1), the advertising expenditure is divided equally between the two parties in the centralized scenario; however, the retailer must spend more share on advertising in the manufacturer-leader equilibria.

The retailer as the manufacturer's follower gains the lowest profit regardless of the scenarios. However, the manufacturer's profit in the decentralized scenarios varies based on the value of the constant $\beta$. When the manufacturer and retailer cooperate, the whole supply chain always gains the highest profit. In order to compare the supply chain efficiency of the Nash and the manufacturer-leader equilibria against the global optima of the centralized case, a deviation value is defined through Eq. (51).

$$
\Delta=\frac{\pi_{c}-\left(\pi_{r}+\pi_{s}\right)}{\pi_{r}+\pi_{s}} .
$$

Table 6 shows the values of $\Delta$ for the five problem instances. As observed, the extent of improvements in the cooperation of the manufacturer and retailer

Table 5. The equilibrium solution in the three game settings.

\begin{tabular}{|c|c|c|c|c|c|c|c|c|c|}
\hline & Problems & $q^{*}$ & $p^{*}$ & $n^{*}$ & $e^{*}$ & $\boldsymbol{w}^{*}$ & $\pi_{s}^{*}$ & $\pi_{r}^{*}$ & $\pi_{T}^{*}$ \\
\hline \multirow{5}{*}{ 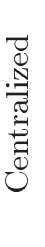 } & Instance 1 & 197,531 & 408 & 35,214 & 35,214 & & & & $8,127,980$ \\
\hline & Instance 2 & 191,617 & 502 & 99,962 & 624,762 & & & & $9,917,252$ \\
\hline & Instance 3 & 229,226 & 923 & $1,916,916$ & 479,229 & & & & $40,559,507$ \\
\hline & Instance 4 & 267,335 & 1,237 & $1,152,080$ & $4,608,321$ & & & & $83,916,380$ \\
\hline & Instance 5 & 310,680 & 1,740 & $14,190,216$ & 14,190216 & & & & $160,707,852$ \\
\hline \multirow{5}{*}{ 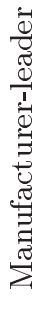 } & Instance 1 & 217,961 & 203 & 6,847 & 34,346 & 176,549 & $3,353,650$ & 506,776 & $3,860,427$ \\
\hline & Instance 2 & 208,547 & 244 & 19,985 & 612,938 & 174,137 & $3,426,094$ & $2,097,458$ & $5,523,552$ \\
\hline & Instance 3 & 267,321 & 431 & 282,815 & 440,531 & 186,590 & $11,169,377$ & $9,948,964$ & $21,118,341$ \\
\hline & Instance 4 & 330,914 & 581 & 144,796 & $3,959,357$ & 198,052 & $21,965,825$ & $19,897,599$ & $41,863,424$ \\
\hline & Instance 5 & 399,340 & 698 & $1,303,022$ & $10,836,721$ & 205,660 & $30,580,115$ & $30,469,917$ & $61,050,031$ \\
\hline \multirow{5}{*}{ 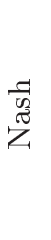 } & Instance 1 & 217284 & 210 & 6400 & 34133 & 176000 & $3,356,848$ & 957,447 & $4,314,295$ \\
\hline & Instance 2 & 210,778 & 211 & 25,600 & 626,125 & 176,000 & $3,377,238$ & $1,651,213$ & $5,028,451$ \\
\hline & Instance 3 & 252149 & 604 & 102400 & 391944 & 176000 & $9,656,210$ & $25,797,008$ & $35,453,218$ \\
\hline & Instance 4 & 294069 & 936 & 25600 & 3126735 & 176000 & $14,979,764$ & $60,950,857$ & $75,930,621$ \\
\hline & Instance 5 & 341748 & 1213 & 160000 & 7936400 & 176000 & $19,413,718$ & $119,626,159$ & $139,039,877$ \\
\hline
\end{tabular}


Table 6. Improvement to supply chain benefit in the centralized scenario.

\begin{tabular}{ccc}
\hline Problems & $\boldsymbol{\Delta}_{\text {manufacturer-leader }}$ & $\boldsymbol{\Delta}_{\text {Nash }}$ \\
\hline Instance 1 & $111 \%$ & $88 \%$ \\
Instance 2 & $80 \%$ & $97 \%$ \\
Instance 3 & $92 \%$ & $14 \%$ \\
Instance 4 & $100 \%$ & $11 \%$ \\
Instance 5 & $163 \%$ & $16 \%$ \\
\hline
\end{tabular}

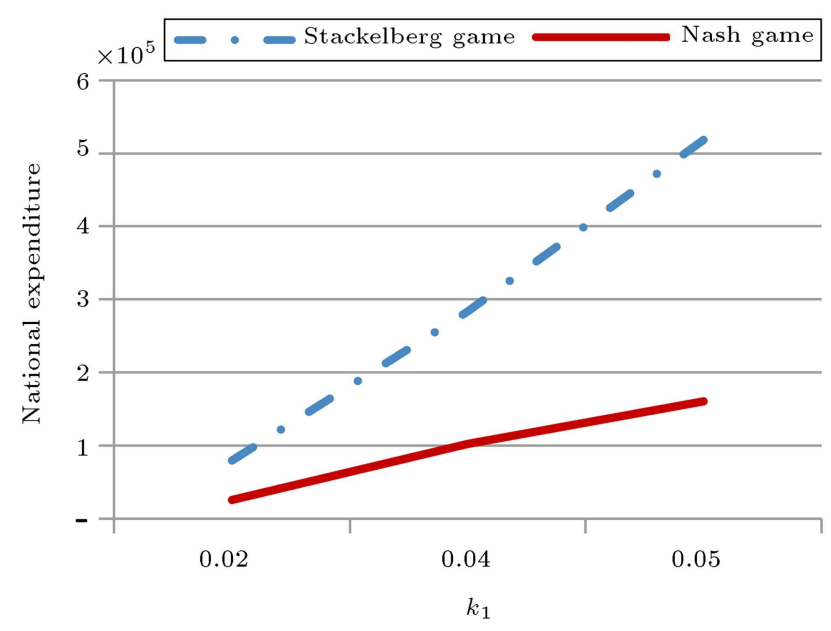

Figure 1. Effect of $k_{1}$ on the manufacturer's national advertising expenditure.

can be influenced by the parameters of the demand function. Nevertheless, the benefits of cooperation are often much more when the two parties do not have the same power and position.

\section{Sensitivity analysis}

Here, sensitivity analysis is carried out to show the impacts of the changes in the main parameters of the proposed demand function on the model outcomes.

First, the analysis is conducted to illustrate how sensitive the value of national advertising expenditure is by the changes in demand elasticity parameter $k_{1}$ while keeping the other parameters constant. Figure 1 indicates that increasing $k_{1}$ motivates the manufacturer to spend more capital on advertising and this motivation is always greater in the manufacturer-leader scenario where the manufacturer acts as the leader and chooses his strategies first to maximize the profit.

Second, in order to show the impact of local advertising expenditure elasticity of demand, $k_{2}$ is changed, while the other parameters are kept constant, the results of which are shown in Figure 2. As expected, an increment in the value of $k_{2}$ makes the demand more elastic to local advertising expenditure; therefore, the retailer raises his expenditure on advertising in order to receive higher demand. Furthermore, the advertising share of the retailer is higher in the manufacturer-

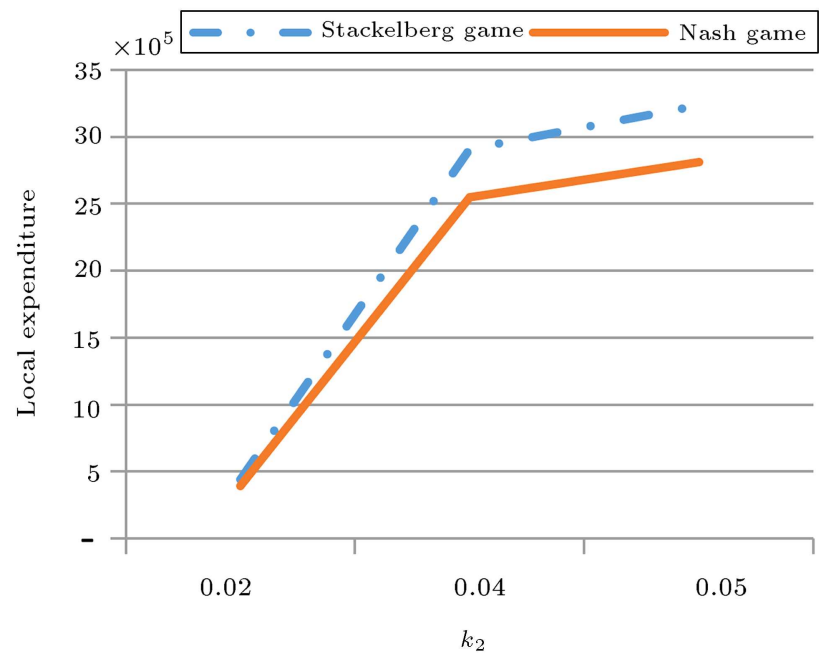

Figure 2. Effect of $k_{2}$ on the retailer's local advertising expenditure.

leader scenario than that in the simultaneous game scenario, because the retailer, as the follower, observes the decisions made by the manufacturer as the leader and then, does his best to increase his own profit. Therefore, the retailer spends more capital on advertising to ensure higher demand.

Third, to analyze the sensitivity of the outcomes to the changes in price elasticity of demand, the value of parameter $b$ is increased, the results of which are depicted in Figures 3 and 4 . Figure 3 implies that the greater the value of the parameter $b$, the lower the price offered by the retailer. When $b$ is high, the demand is more elastic to price. Thus, the retailer has to reduce the price of commodity to gain higher demand. As an immediate result, the whole supply chain earns less profit at a lower retail price. This result can be observed in all the three game scenarios.

Figure 4 depicts the impact of price $f$ and national advertising expenditures raise by increasing parameter $b$. In fact, the retailer needs to reduce the costs in order to be able to offer lower retail price; therefore, he spends less on local advertising. In the decentralized channel, the manufacturer competes with the retailer and sets lower national advertising expenditure in response to the retailer's strategies. Advertising expenditures drop due to price elasticity factor growth, also observed in the centralized scenario. Under this scenario, the two parties concur on lower advertising expenditures to reduce the whole supply chain costs. In fact, low retail prices do not allow high expenditures on advertising.

\section{Conclusion}

The present study aims to investigate the coordination of supply chain decisions in a manufacturerretailer network using three different game theoretic 

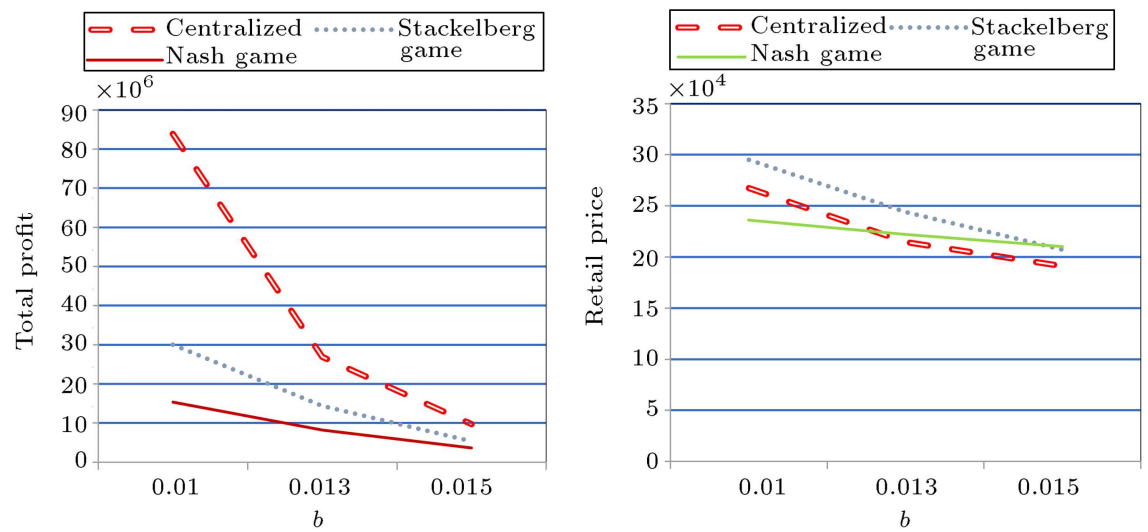

Figure 3. Effect of price elasticity factor $b$ on the retail prices and the supply chain total profit.
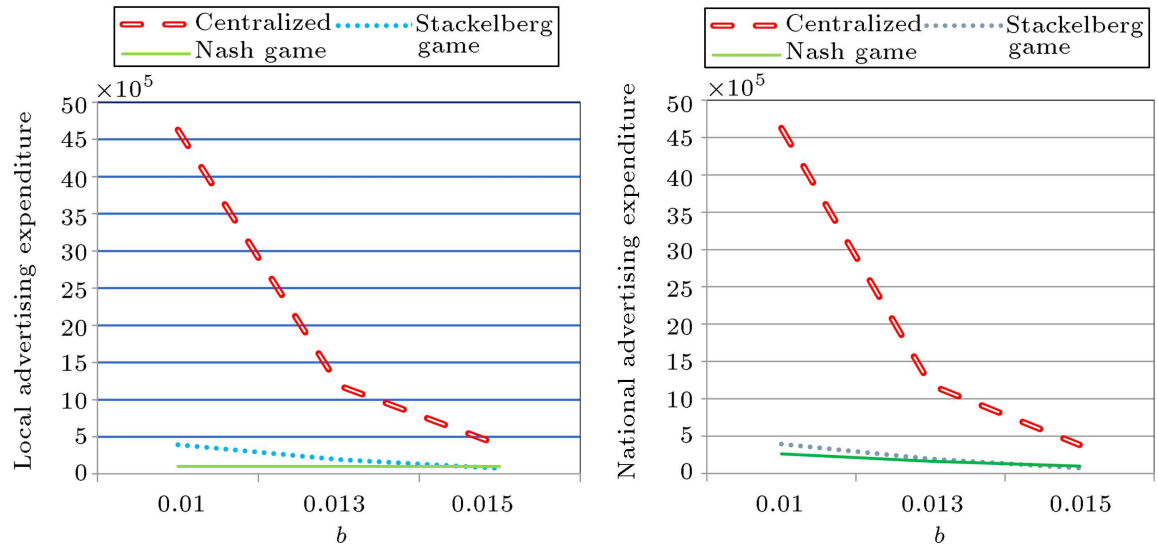

Figure 4. Effect of price elasticity factor $b$ on the local advertising expenditure and the national advertising expenditure.

approaches including Stackelberg manufacturer game, Nash game, and centralized scenarios. Then, the retail price, wholesale price, economic order quantity, optimal retailer advertising costs, and the manufacturer national advertising expenditures were determined in the newsboy model. Demand was assumed stochastic and influenced by both retail price and advertising expenditures. The equilibrium solutions were obtained exactly within three different market structures. Some corollaries are presented and theoretically proved to show the relations among optimal decision variables in both centralized and decentralized scenarios.

The obtained results showed that an increase in demand elasticity coefficient led to a remarkable reduction in the retail price, economic order quantity, local and national advertising expenditures, and profit of the supply chain. On the contrary, both local and national advertising costs increase with an increase in the advertising function coefficient. The ratio of national advertising costs to local advertising costs in the centralized channel condition is higher than that in the Stackelberg or Nash games. In fact, the proportion of advertising expenses in the centralized channel is more than that of its rivals. Moreover, it was found that in the centralized structure, advertising expenditures were always higher than the decentralized setting. In the centralized structure, the order quantity was higher than the decentralized state, while it was lower for the retail price. However, the profit for members in the centralized scenario was always more than that in the proposed Nash and Stackelberg games.

As suggestions for future research, one can consider other types of contracts such as revenue sharing contract and return policy using the newsboy problem approach with stochastic demand. Besides, applying Stackelberg retailer game to a three-tier supply chain with advertising and price-dependent demand when the manufacturer is the dominant power can be an interesting research area.

\section{References}

1. Dridi, D. and Ben Youssef, S. "A game theoretic framework for competing/cooperating retailers under price and advertising dependent demand", Munich Personal RePEc Archive, available at: https://mpra.ub.unimuenchen.de/62705/ (2015).

2. Berger, P. "Vertical cooperative advertising ventures", J. of Mark. Res., 9(3), pp. 309-312 (1972).

3. Aust, G. and Buscher, U. "Cooperative advertising 
models in supply chain management: A review", Eur. J. of Oper. Res., 234(1), pp. 1-14 (2014).

4. Huang, Z. and Li, S.X. "Co-op advertising models of manufacturer-retailer supply chains: A game theoretic approach", Eur. J. of Oper. Res., 135, pp. 527-544 (2001).

5. Xie, J. and Wei, J.C. "Coordinating advertising and pricing in a manufacturer-retailer channel", Eur. J. of Oper. Res., 197, pp. 785-791 (2009).

6. Karray, S. and Amin, S.H. "Cooperative advertising in a supply chain with retail competition", Int. J. of Prod. Res., 53(1), pp. 88-105 (2015).

7. Yan, R., Cao, Z., and Pei, Z. "Manufacturer's cooperative advertising, demand uncertainty, and information sharing", J. of Bus. Res., 69(2), pp. 709-717 (2016).

8. J $\phi$ rgensen, S. and Zaccour, G. "A survey of gametheoretic models of cooperative advertising", Eur. J. of Oper. Res., 237(1), pp. 1-14 (2014).

9. Alirezaei, A. and Khoshalhan, F. "Coordination of pricing and co-op advertising models in supply chain: A game theoretic approach", Int. J. of Ind. Eng. Comput., 5, pp. 23-40 (2014).

10. He, X., Prasad, A., and Sethi, S.P. "Cooperative advertising and pricing in a dynamic stochastic supply chain: Feedback Stackelberg strategies", Prod. and Oper. Manag., 18, pp. 78-94 (2009).

11. Szmerekovsky, J.G. and Zhang, J. "Pricing and twotier advertising with one manufacturer and one retailer", Eur. J. of Oper. Res., 192(3), pp. 904-917 (2009).

12. Xie, J. and Neyret, A. "Computers \& industrial engineering co-op advertising and pricing models in manufacturer - retailer supply chains", Comput. \& Ind. Eng., 56(4), pp. 1375-1385 (2009).

13. Chen, T.H. "Effects of the pricing and cooperative advertising policies in a two-echelon dual-channel supply chain", Comput. \& Ind. Eng., 87, pp. 250-259 (2015).

14. Seyed Esfahani, M.M., Biazaran, M., and Gharakhani, M. "A game theoretic approach to coordinate pricing and vertical co-op advertising in manufacturer-retailer supply chains", Eur. J. of Oper. Res., 211, pp. 263273 (2011).

15. Naimi Sadigh, A., Chaharsooghi, S.K., and Sheikhmohammady, M. "Game-theoretic analysis of coordinating pricing and marketing decisions in a multi-product multi-echelon supply chain", Sci. Iran, 23(3), pp. 1459-1473 (2016).

16. Choi, S. "Price competition in a channel structure with a common retailer", Mark. Sci., 10(4), pp. 271-296 (1991).
17. Aust, G. "Vertical cooperative advertising and pricing decisions in a manufacturer-retailer supply chain: a game-theoretic approach", In Vertical Cooperative Advertising in Supply Chain Management, pp. 65-99, Springer International Publishing (2015).

18. Ke, H., Wu, Y., Huang, H., and Chen, Z. "Pricing decision in a two-echelon supply chain with competing retailers under uncertain environment", $J$. of Uncertain. Anal. and Appl., 5(1), p. 5 (2017). DOI: 10.1186/s40467-017-0059-2

19. Naimi Sadigh, A., Karimi, B., and Zangirani Farahani, R. "A game theoretic approach for two echelon supply chains with continuous depletion", Int. J. of Manag. Sci. and Eng. Manag., 6(6), pp. 408-412 (2011).

20. Amirtaheri, O., Zandieh, M., and Dorri, B. "A bi-level programming model for decentralized manufacturerdistributer supply chain considering cooperative advertising", Sci. Iran., 25(2), pp. 891-910 (2017).

21. Zhou, Y-Wu, Li, J., and Zhong, Y. "Cooperative advertising and ordering policies in a two-echelon supply chain with risk-averse agents", Omega, 75, pp. 97-117 (2018).

22. Petruzzi, N.C. and Dada, M. "Pricing and the newsvendor problem: a review with extensions", Oper. Res., 47(2), pp. 183-194 (1999).

\section{Appendix A}

Theorem 1. If the Hessian matrix is negative semidefinite, $f(x, y)$ is pseudo-concave.

Theorem 2. The Hessian matrix $H$ is negative semidefinite, if and only if:

$$
[x, y] \times \mathrm{H} \times\left[\begin{array}{l}
x \\
y
\end{array}\right] \leq 0 .
$$

The Hessian matrix of the centralized supply chain's objective function is derived as follows:

$$
\begin{aligned}
\mathrm{H} & =\left[\begin{array}{cccc}
\frac{\partial \pi}{\partial p^{2}} & \frac{\partial \pi}{\partial p \partial z} & \frac{\partial \pi}{\partial p \partial n} & \frac{\partial \pi}{\partial p \partial e} \\
\frac{\partial \pi}{\partial z \partial p} & \frac{\partial \pi}{\partial z^{2}} & \frac{\partial \pi}{\partial z \partial n} & \frac{\partial \pi}{\partial z \partial e} \\
\frac{\partial \pi}{\partial n \partial p} & \frac{\partial \pi}{\partial n \partial z} & \frac{\partial \pi}{\partial n^{2}} & \frac{\partial \pi}{\partial n \partial e} \\
\frac{\partial \pi}{\partial e \partial p} & \frac{\partial \pi}{\partial e \partial z} & \frac{\partial \pi}{\partial e \partial n} & \frac{\partial \pi}{\partial e^{2}}
\end{array}\right] \\
& =\left[\begin{array}{cccc}
-2 b & 1-F(z) & \frac{k_{1}}{2 \sqrt{n}} & \frac{k_{2}}{2 \sqrt{e}} \\
1-F(z) & -p f(z) & 0 & 0 \\
\frac{k_{1}}{2 \sqrt{n}} & 0 & -\frac{k_{1}(p-c)}{4 \sqrt{n^{3}}} & 0 \\
\frac{k_{2}}{2 \sqrt{e}} & 0 & 0 & -\frac{k_{2}(p-c)}{4 \sqrt{e^{3}}}
\end{array}\right] .
\end{aligned}
$$

Using Theorems 1 and 2, we have: 
$\left[\begin{array}{llll}p & z & n & e\end{array}\right]\left[\begin{array}{cccc}\frac{\partial \pi}{\partial p^{2}} & \frac{\partial \pi}{\partial p \partial z} & \frac{\partial \pi}{\partial p \partial n} & \frac{\partial \pi}{\partial p \partial e} \\ \frac{\partial \pi}{\partial z \partial p} & \frac{\partial \pi}{\partial z^{2}} & \frac{\partial \pi}{\partial z \partial n} & \frac{\partial \pi}{\partial z \partial e} \\ \frac{\partial \pi}{\partial n \partial p} & \frac{\partial \pi}{\partial n \partial z} & \frac{\partial \pi}{\partial n^{2}} & \frac{\partial \pi}{\partial n \partial e} \\ \frac{\partial \pi}{\partial e \partial p} & \frac{\partial \pi}{\partial e \partial z} & \frac{\partial \pi}{\partial e \partial n} & \frac{\partial \pi}{\partial e^{2}}\end{array}\right]$

$\left[\begin{array}{l}p \\ z \\ n \\ e\end{array}\right]=\left[\begin{array}{llll}p & z & n & e\end{array}\right]$

$\left[\begin{array}{cccc}-2 b & 1-F(z) & \frac{k_{1}}{2 \sqrt{n}} & \frac{k_{2}}{2 \sqrt{e}} \\ 1-F(z) & -p f(z) & 0 & 0 \\ \frac{k_{1}}{2 \sqrt{n}} & 0 & -\frac{k_{1}(p-c)}{4 \sqrt{n^{3}}} & 0 \\ \frac{k_{2}}{2 \sqrt{e}} & 0 & 0 & -\frac{k_{2}(p-c)}{4 \sqrt{e^{3}}}\end{array}\right]$

$\left[\begin{array}{l}p \\ z \\ n \\ e\end{array}\right]=8 z c(1-F(z))^{2}+4\left(\left(k_{1}+k_{2}\right) c^{2} F(z)\right.$

$\left.-\left(k_{1}+k_{2}\right) c^{2} F^{2}(z)\right)-8 b c^{2}-f(z) c z^{2}$

$(1-F(z)) \leq 0$.

While analyzing the numerical results, $A<z^{*}<B$ shows that Eq. (A.2) is always non-positive and the Hessian matrix is negative pseudo-definite. Thus, optimality conditions are elicited by taking derivatives of the profit function.

\section{Appendix B}

The Hessian matrix of the retailer's profit function is given by:

$$
\begin{aligned}
\mathrm{H} & =\left[\begin{array}{ccc}
\frac{\partial \pi}{\partial p^{2}} & \frac{\partial \pi}{\partial p \partial z} & \frac{\partial \pi}{\partial p \partial e} \\
\frac{\partial \pi}{\partial z \partial p} & \frac{\partial \pi}{\partial z^{2}} & \frac{\partial \pi}{\partial z \partial e} \\
\frac{\partial \pi}{\partial e \partial p} & \frac{\partial \pi}{\partial e \partial z} & \frac{\partial \pi}{\partial e^{2}}
\end{array}\right] \\
& =\left[\begin{array}{ccc}
-2 b & 1-F(Z) & \frac{k_{2}}{2 \sqrt{e}} \\
1-F(Z) & -p f(z) & 0 \\
\frac{k_{2}}{2 \sqrt{e}} & 0 & -\frac{k_{2}(p-w)}{4 \sqrt{e^{3}}}
\end{array}\right] .
\end{aligned}
$$

Using Theorems 1 and 2, we have:

$$
\begin{aligned}
& {\left[\begin{array}{lll}
p & z & e
\end{array}\right]\left[\begin{array}{ccc}
\frac{\partial \pi}{\partial p^{2}} & \frac{\partial \pi}{\partial p \partial z} & \frac{\partial \pi}{\partial p \partial e} \\
\frac{\partial \pi}{\partial z \partial p} & \frac{\partial \pi}{\partial z^{2}} & \frac{\partial \pi}{\partial z \partial e} \\
\frac{\partial \pi}{\partial e \partial p} & \frac{\partial \pi}{\partial e \partial z} & \frac{\partial \pi}{\partial e^{2}}
\end{array}\right]\left[\begin{array}{l}
p \\
z \\
e
\end{array}\right]} \\
& \quad=2 w z+\frac{w^{2} k^{2}{ }_{2} F(z) c}{2(1-F(z))}+\frac{w^{2} k_{2}^{3} F(z)}{2(1-F(z))^{2}}
\end{aligned}
$$

$$
-\frac{2 b w^{2}}{(1-F(z))^{2}}-\frac{w z^{2} f(z)}{(1-F(z))}-\frac{k_{2}}{2} \leq 0
$$

After analyzing numerical results, $A<z^{*}<B$ shows that Eq. (B.2) holds, the solution is unique, and the Hessian matrix is negative pseudo-definite. Thus, optimality conditions are extracted by taking derivatives of the profit function.

\section{Appendix C}

The Hessian matrix of the manufacturer's profit function is obtained as follows:

$$
\begin{aligned}
\mathrm{H} & =\left[\begin{array}{cc}
\frac{\partial \pi}{\partial w^{2}} & \frac{\partial \pi}{\partial w \partial n} \\
\frac{\partial \pi}{\partial n \partial w} & -\frac{k_{1}(w-c)}{4 \sqrt{n^{3}}}
\end{array}\right] \\
& =\left[\begin{array}{cc}
0 & \frac{k_{1}}{2 \sqrt{n}} \\
\frac{k_{1}}{2 \sqrt{n}} & -\frac{k_{1}(w-c)}{4 \sqrt{n^{3}}}
\end{array}\right] .
\end{aligned}
$$

Using Theorems 1 and 2, we have:

$$
\begin{aligned}
& {\left[\begin{array}{ll}
w & n
\end{array}\right] \mathrm{H}\left[\begin{array}{l}
w \\
n
\end{array}\right] } \\
& {\left[\begin{array}{ll}
w & n
\end{array}\right]\left[\begin{array}{cc}
0 & \frac{k_{1}}{2 \sqrt{n}} \\
\frac{k_{1}}{2 \sqrt{n}} & -\frac{k_{1}(w-c)}{4 \sqrt{n^{3}}}
\end{array}\right]\left[\begin{array}{l}
w \\
n
\end{array}\right] } \\
&=\frac{w n k_{1}}{\sqrt{n}}-\frac{n k_{1}(w-c)}{4 \sqrt{n}} \leq 0 \Rightarrow c \leq w(n-1) .
\end{aligned}
$$

Since inequality $c \leq w(n-1)$ always holds, the Hessian matrix is negative semi-definite. Therefore, the optimality conditions of the wholesaler's profit function are derived from taking the derivatives.

\section{Appendix D}

\section{Stackelberg game versus centralized channel scenario}

Since the retail price value $p$ is always higher than the wholesale price $w, p-c$ will be always higher than $w-c$ as well. Consequently, national advertising expenditures in the centralized supply chain are higher than national advertising costs in Eq. (32) in the decentralized scheme; thus, $n_{d}^{*}<n_{c}^{*}$.

Since the retail price $p$ is always higher than the wholesale price $\mathrm{w}$ and the numerator is multiplied by $F(Z)$ which is a real number between 0 and 1 , the following relation holds:

$$
w * \frac{F(Z)}{1-F(Z)} \leq p-c .
$$

Thus we have $e_{d}^{*}<e_{c}^{*}$. 
The retail price in the decentralized channel is given in Eq. (35). Since the wholesale price $w$ is always higher than the unit production cost $c$, based on Eq. (16), it can be easily proved that $p_{d}^{*}>p_{c}^{*}$.

According to the following equation:

$$
\begin{aligned}
q_{c}^{*}= & z^{*}+d(p)+h(n, e)=z^{*} \\
& +\left(a-b p^{*}+k_{1} \sqrt{n^{*}}+k_{2} \sqrt{e^{*}}\right),
\end{aligned}
$$

since in the decentralized configuration $n$ and $e$ are low and $p$ is high, the economic order quantity, which is obtained from algebraic addition of the local and national advertising costs when the retail price is subtracted, is always smaller than that in the centralized structure and $q_{d}^{*}<q_{c}^{*}$.

Nash game versus centralized channel scenario Note that $n_{d}^{*}<n_{c}^{*}$ : for $\beta>1, p-c$ is always higher than $c(\beta-1)$ because the retail price $p$ is always higher than the production cost $c$. Hence, the national advertising costs of the centralized structure are higher than those of Eq. (41) in the decentralized setting.

Given that $e_{d}^{*}<e_{c}^{*}$, since the retail price $p$ is always higher than $c$ and the numerator is multiplied by $F(Z)$ which is a real number between 0 and 1 , the following relation holds:

$$
\frac{\beta F(Z)}{1-F(Z)} \leq p-c .
$$

Thus we have $e_{d}^{*}<e_{c}^{*}$.

Given that $p_{d}^{*}>p_{c}^{*}$, since the retail price in the Nash structure (Eq. (42)), $0 \leq F(Z) \leq 1$, and the wholesale price $w$ are always higher than the unit production cost $c(w=\beta c$ where $\beta>0)$, it can be proved that the inequality $p_{d}^{*}>p_{c}^{*}$ holds.

Given that $q_{d}^{*}<q_{c}^{*}$, consider the three previous properties and the relation $q_{c}^{*}=z^{*}+d(p)+h(n, e)=$ $z^{*}+\left(a-b p^{*}+k_{1} \sqrt{n^{*}}+k_{2} \sqrt{e^{*}}\right)$. Since $n$ and $e$ are low and $p$ is high in the Nash setting, the order quantity, which is obtained from algebraic addition of the local and national advertising costs when the retail price is subtracted, will be always smaller than that of the centralized structure.

\section{Appendix E}

Stackelberg game versus centralized channel scenario

$$
\begin{aligned}
& n_{d}^{*} / e_{d}^{*} \Rightarrow \frac{n^{*}=\left(\frac{\left(w^{*}-c\right) k_{1}}{2}\right)^{2}}{e^{*}=\left(\frac{k_{2} w^{*} F(z)}{2(1-F(z))}\right)^{2}}=\frac{k_{1}}{k_{2}}\left(1-\frac{c}{w}\right)(1-F(z)), \\
& n_{c}^{*} / e_{c}^{*} \Rightarrow \frac{n_{c}^{*}=\left(\frac{k_{1}\left(p^{*}-c\right)}{2}\right)^{2}}{e_{c}^{*}=\left(\frac{k_{2}\left(p^{*}-c\right)}{2}\right)^{2}}=\frac{k_{1}}{k_{2}}
\end{aligned}
$$

According to Eq. (E.1), since $\left(1-\frac{c}{w}\right)(1-F(z))$ is always smaller than 1 , Corollary 2 always holds. This property indicates that the ratio of local to the national advertising costs in the Stackelberg game is always smaller than that in the centralized scenario.

Nash game versus centralized channel scenario

$$
\begin{gathered}
n_{d}^{*} / e_{d}^{*} \Rightarrow \frac{n^{*}=\left(\frac{c(\beta-1) k_{1}}{2}\right)^{2}}{e^{*}=\left(\frac{\beta k_{2} F(z)}{2(1-F(z))}\right)^{2}}=\frac{k_{1}}{k_{2}}\left(\frac{\beta-1}{\beta}\right)\left(\frac{1-F(z)}{F(z)}\right) \\
\beta \geq 1 \text { and } 0 \leq F(Z) \leq 1, \\
n_{c}^{*} / e_{c}^{*} \Rightarrow \frac{n_{c}^{*}=\left(\frac{k_{1}\left(p^{*}-c\right)}{2}\right)^{2}}{e_{c}^{*}=\left(\frac{k_{2}\left(p^{*}-c\right)}{2}\right)^{2}}=\frac{k_{1}}{k_{2}} .
\end{gathered}
$$

\section{Appendix F}

\section{Stackelberg game versus centralized channel scenario}

$d n_{d}^{*} / d k_{1}>0$ where :

$$
n^{*}=\left(\frac{\left(w^{*}-c\right) k_{1}}{2}\right)^{2} \Rightarrow \frac{d n_{d}^{*}}{d k_{1}}=\left(w^{*}-c\right) k_{1}>0
$$

$d e_{d}^{*} / d k_{2}>0$ where :

$$
e^{*}=\left(\frac{k_{2} w^{*} F(z)}{2(1-F(z))}\right)^{2} \Rightarrow \frac{d e_{d}^{*}}{d k_{2}}=\frac{k_{2} w^{*} F(z)}{(1-F(z))}>0
$$

$\partial q_{d}^{*} / d k_{2}>0$ where :

$$
q=z+\left(a-b p+k_{1} \sqrt{n}+k_{2} \sqrt{e}\right) \Rightarrow \frac{\partial q_{d}^{*}}{d k_{2}}=\sqrt{e}>0
$$

$\partial q_{d}^{*} / d k_{1}>0$ where :

$$
q=z+\left(a-b p+k_{1} \sqrt{n}+k_{2} \sqrt{e}\right) \Rightarrow \frac{\partial q_{d}^{*}}{d k_{2}}=\sqrt{n}>0 .
$$

Nash game versus centralized channel scenario $d n_{d}^{*} / d k_{1}>0$ where:

$$
n=\left(\frac{c(\beta-1) k_{1}}{2}\right)^{2} \Rightarrow \frac{d n_{d}^{*}}{d k_{1}}=\frac{1}{2} c^{2}(\beta-1)^{2} k_{1}>0,
$$

$d e_{d}^{*} / d k_{2}>0$ where :

$$
e_{d}^{*}=\left(\frac{\beta k_{2} F(z)}{2(1-F(z))}\right)^{2} \Rightarrow \frac{d e_{d}^{*}}{d k_{2}}=\frac{k_{2}(\beta F(z))^{2}}{2(1-F(z))^{2}}>0,
$$

$\partial q_{d}^{*} / d k_{2}>0$ where :

$$
q=z+\left(a-b p+k_{1} \sqrt{n}+k_{2} \sqrt{e}\right) \Rightarrow \frac{\partial q_{d}^{*}}{d k_{2}}=\sqrt{e}>0
$$




$$
\begin{aligned}
& \partial q_{d}^{*} / d k_{1}>0 \text { where : } \\
& \qquad q=z+\left(a-b p+k_{1} \sqrt{n}+k_{2} \sqrt{e}\right) \Rightarrow \frac{\partial q_{d}^{*}}{d k_{2}}=\sqrt{n}>0 .
\end{aligned}
$$

\section{Appendix G}

According to Eqs. (40) and (42), it can concluded that $d w / d \beta>0$ and $d p^{*} / d \beta>0$. This conclusion is drawn from the following relations:

$d w / d \beta$ where :

$$
w=\beta c \Rightarrow d w / d \beta=w>0
$$

$d p^{*} / d \beta \quad$ where :

$$
p=\frac{\beta c}{1-F(z)} \Rightarrow d p^{*} / d \beta=\frac{c}{1-F(z)}>0
$$

Obviously, an increase in $\beta$ value leads to an increase in both retail and wholesale prices.

\section{Biographies}

Hamid Ghashghaei received his BSc and MSc degrees in Industrial Engineering from Islamic Azad University, Tehran, Iran. His research interests include operations research and supply chain management.

Marzieh Mozafari is currently a Faculty Member at the Department of Industrial Engineering at Islamic Azad University, Tehran. She holds PhD in Industrial Engineering from the Amirkabir University of Technology, Tehran, Iran. Her research interests include mathematical modeling and game theory, pricing and revenue management in the area of supply chain management, and transportation planning. 